\title{
SPECTROSCOPIC INVESTIGATION ON PAINT LAYERS OF SABIL-KUTTAB UMM 'ABBAS CEILING, MOHAMMED ALI ERA IN CAIRO, EGYPT: IDENTIFICATION OF UNUSUAL PIGMENT AND MEDIUM
}

\author{
Abdel-Ghani, M. ${ }^{1} \&$ Mahmoud, M. ${ }^{2}$ \\ ${ }^{1}$ Lecturer, Conservation dept., Faculty of Archaeology, Cairo Univ., Giza, Egypt. \\ ${ }^{2}$ Supreme Council of Antiquities (SCA), Egypt \\ E-mail:mabdelghani2001@yahoo.com
}

\begin{abstract}
A comprehensive study has been undertaken into Sabil-Kuttab Umm 'Abbas ceiling (1867 $A D / 1284 \mathrm{H})$ in Cairo, Egypt. The study included both organic and inorganic constituents comprising; the pigments, the paint media, the gold layer and the white ground layer. The analytical instruments chosen for the study were Raman microscopy, Fourier transform infra red spectroscopy coupled with attenuated total reflection (FTIR-ATR) and optical microscopy. The pigments identified were ultramarine blue $\mathrm{Na}_{6}\left[\mathrm{Al}_{6} \mathrm{Si}_{6} \mathrm{O}_{24}\right] \mathrm{Sn}$, indigo $\left(\mathrm{C}_{16} \mathrm{H}_{10} \mathrm{~N}_{2} \mathrm{O}_{2}\right)$, vermilion $(\alpha-\mathrm{HgS})$, red ochre $\left(\mathrm{Fe}_{2} \mathrm{O}_{3}+\right.$ Clay+silica), barium white $\left(\mathrm{BaSO}_{4}\right)$, lead white $\left[2 \mathrm{PbCO}_{3}\right.$. $\left.\mathrm{Pb}(\mathrm{OH})_{2}\right]$ and cobalt yellow $\left(\mathrm{K}_{3}\left[\mathrm{Co}\left(\mathrm{NO}_{2}\right)_{6}\right]\right)$. The chromate mineral, hemihedrite $\left(\mathrm{ZnPb}_{10}\left(\mathrm{CrO}_{4}\right)_{6}\left(\mathrm{SiO}_{4}\right)_{2} \mathrm{~F}_{2}\right)$, was detected for the first time as an artistic pigment in this study. The paint media revealed were animal glue admixed with linseed oil and mastic resin. The detection of mastic resin as a paint medium in Egyptian paintings is of interest. The white ground layer was found to consist of calcium sulfate dihydrate $\left(\mathrm{CaSO}_{4} \cdot 2 \mathrm{H}_{2} \mathrm{O}\right)$ and calcite $\left(\mathrm{CaCO}_{3}\right)$ admixed with animal glue.
\end{abstract}

Keywords: Sabil, Kuttab, Umm Abbas, Mohammad Ali Era, Raman spectroscopy, FTIR, Hemihedrite, Mastic

\section{Introduction}

On the occasion of conservation process of sabil-kuttab Umm 'Abbas, fig. (1), analytical investigation on the materials used in the wooden ceiling and the surrounding cornice has been undertaken. The ceiling under study is located in a charitable foundation composed of a sabil, public water dispensary, and a kuttab, an elementary Quranic school for children. The sabil is usually located on the ground floor with the kuttab above it on the first floor. The sabil is roofed by a ribbed dome, with a porch below it, to protect Sabil users from the sun and rain. This foundation could be attached to a mosque or be a separate structure, as the one concerned in this study. SabilKuttab Umm 'Abbas 1867 AD/1284 H was built by Bambh Qadin, the granddaughter of Abbas I, who ruled Egypt from 1848 to 1854 AD, and the 
mother of Abbas II. "Umm" in Arabic means mother, so the sabil is called 'the mother of Abbas'. Bambah Qadin was a revered member of the royal family and was called Umm al-Muhsinin 'mother of charity', as she gave away so much of her considerable wealth. The main octagonal façade of the building was decorated with floral and geometrical motifs and garlands, as well as colourful Quranic and poetic inscriptions applied on blue backgrounds [1]. The aim of this investigation is to characterize the paint layers containing pigments and media, and to compare the results achieved with the previous findings from the same period. Both the wooden white ceiling with the relief gilding stucco decorations and the painted cornice were studied.

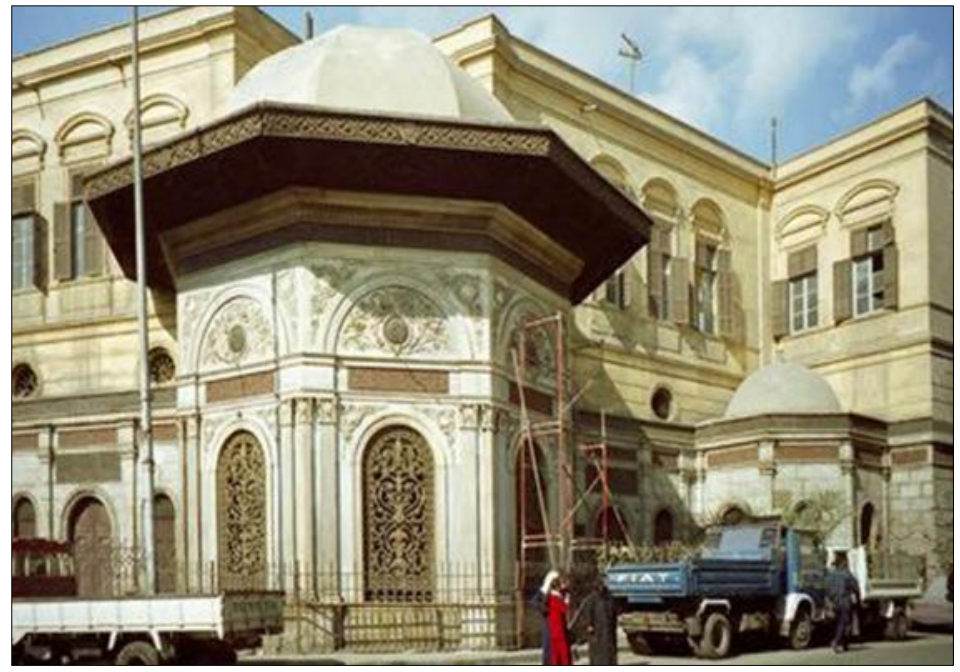

Figure (1) general over view of sabil-kuttab Umm 'Abbas

\section{Materials and Methods}

\subsection{Samples and sample preparation}

Small fragments of the paint layers were embedded in a transparent epoxy resin (Buehler ${ }^{\circledR}$ Epo-Thin ${ }^{\circledR}$ low viscosity epoxy resin No. 20-8140032). Different grades silicon carbide grinding paper was used for grinding

and polishing the cross-sections. The paint samples examined from the wooden ceiling were white and gold, fig. (2-a), while the samples from the cornice were blue, red, brown and yellow, figs. (2-b \& c).
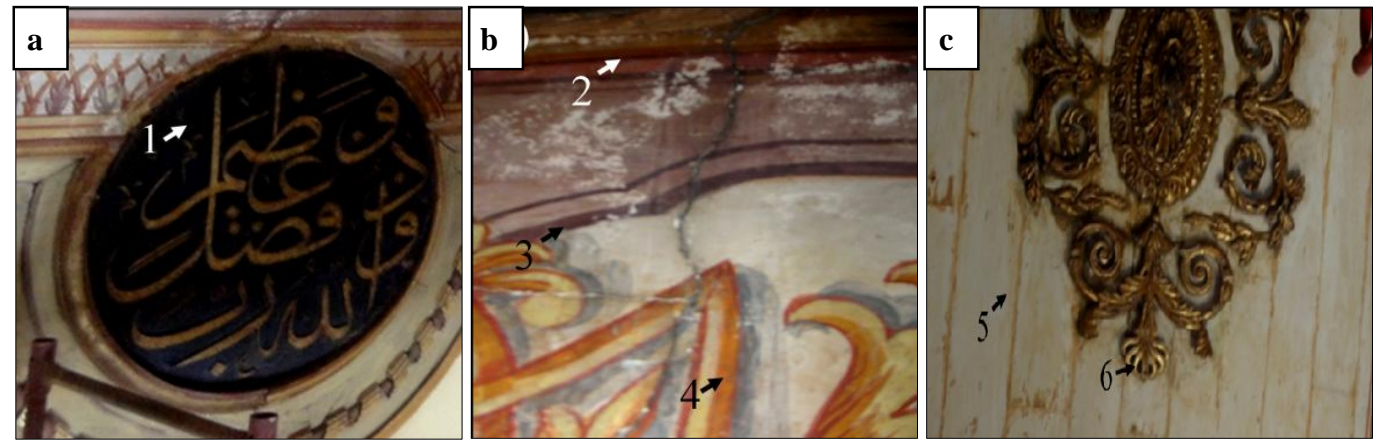

Figure (2) the samples' locations $\underline{\mathbf{a}}$ the golden inscriptions over the blue background (1), $\underline{\mathbf{b}}$ the painted decorations of the cornice; the red sample (2), the brown sample (3), the yellow sample (4), $\underline{\mathbf{c}}$ the wooden ceiling and the stucco relief decoration; the white sample (5), the gold layer (6). 


\subsection{Light microscopy}

Light microscopy is an important tool that could be used for studying capturing and documenting different grades of material deterioration [2]. Paint fragments and cross-sections were studied using a NIKON ECLIPSE ME 600 microscope equipped with an Olympus e-410 digital camera. The magnification varied from $\mathrm{x} 100$ to $\mathrm{x} 400$ depending on the size of the samples.

\subsection{Fourier transform infrared spectroscopy coupled with attenuated total reflection (FTIR-ATR)}

FTIR spectra of the paint media were obtained using a Bruker FTIR spectrometer, model VERTEX 70 equipped with ATR. The IR spectra, in absorbance mode, were obtained from the specimens, using an aperture of $20-100 \mu \mathrm{m}$, in the spectral region 600 to $4000 \mathrm{~cm}^{-1}$. The resolution was $4 \mathrm{~cm}^{-}$

\subsection{Raman microscopy}

A Senterra Raman spectrometer (Bruker) was used in the current work, consisting of a confocal Raman microscope (20× objective lens) with a spectral footprint of about $2 \mu \mathrm{m}, 4$ $\mathrm{cm}^{-1}$ spectral resolution and operating with a laser wavelength of $785 \mathrm{~nm}$.

\section{Results}

Several results were proved through different investigation techniq-

\subsection{The paint layers of the cornice}

\subsubsection{The blue paint sample}

The blue paint was sampled from the background of the inscription in the cornice, fig. (3-a \& b). It was applied as a thick layer that could be easily separated from the white ground layer underneath in order to be analyzed. It was examined by means of the Raman analysis, and the spectrum achieved, fig. (3-c) revealed the vibrational characteristic bands of ultramarine blue, $\mathrm{Na}_{6}\left[\mathrm{Al}_{6} \mathrm{Si}_{6} \mathrm{O}_{24}\right] \mathrm{S}_{\mathrm{n}}$ [5]. The well defined bands of ultramarine, found at 545 and $1091 \mathrm{~cm}^{-1}$, are attributable to the totally symmetric stretch of the radical anion $\mathrm{S}_{3}{ }^{-}$and $\mathrm{S}_{2}{ }^{-}$ [6] [7]. The natural ultramarine is the blue pigment extracted from lapis lazuli, mainly the mineral lazurite, comprising a complex sulfur-containing aluminum silicate [8]. It is suggested was 64 for each spectrum. The FTIR spectrum of the white ground layer, in a freshly prepared $\mathrm{KBr}$ pellet, was obtained using JASCO FT-IR-460 plus spectrometer using an aperture of 20 $100 \mu \mathrm{m}$, in the spectral region 400 $4000 \mathrm{~cm}^{-1}$.

Raman spectra were subjected to baseline correction and smoothed. Then, all resulted compounds were identified through comparing their characteristic vibrational spectra with those in published databases [3] [4].

ues, tools and computer programs, which could be summarized as follows:

that lapis lazuli occurs in the Uweinat oasis in south east Egypt [9]. Artificial ultramarine was first reported in 1827 and was extensively used as an artistic pigment in the second half of the $19^{\text {th }}$ century [8]. In order to manufacture ultramarine blue pigment, anhydrous sodium carbonate or sulfate is mixed with china clay, silica, in the form of sand or quartz, and sulphur in reducing atmosphere. All the ingredients are mixed, finely ground and heated in a furnace at red heat for several hours in the absence of air. The product obtained is green in colour and known as primary or green ultramarine, which is heated again at above $500^{\circ} \mathrm{C}$ to be converted to a blue colour. The final product is ground and washed to get rid of soluble salts and then dried. 


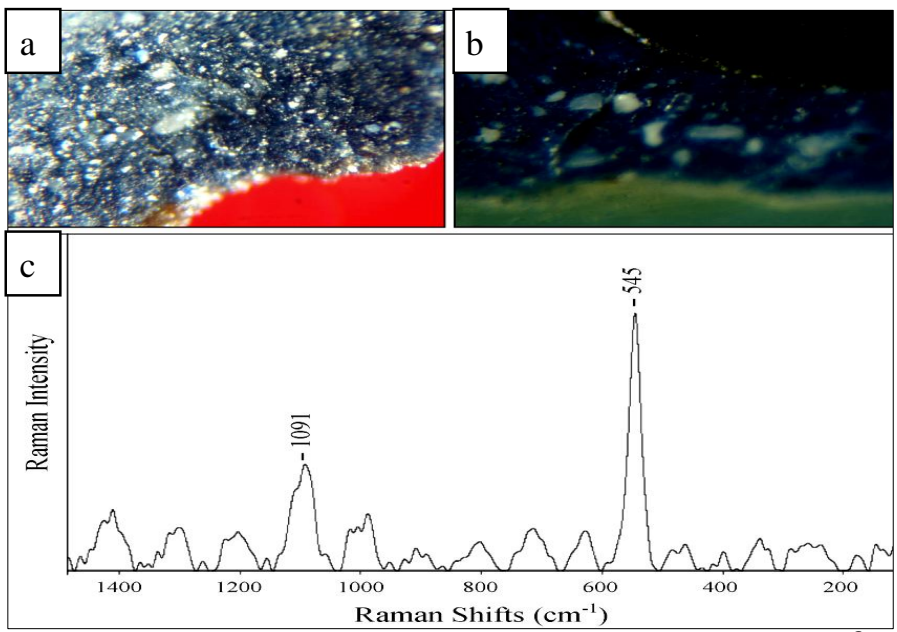

Figure (3) the blue paint sample taken from the inscription's background a the fragment image, $\underline{b}$ the cross-section image, $\underline{c}$ the Raman spectrum.

\subsubsection{The red paint sample}

The fragment image of the red paint sample taken from the cornice showed a red pigment, weakly distributed on the ground layer, fig. (4-a). The crosssection image, fig. (4-b) showed an uneven thin layer of the red paint. The Raman spectrum, fig. (4-c) yielded a complex mixture of cinnabar $(\alpha-\mathrm{HgS})$ and a chromate pigment. Cinnabar revealed its characteristic bands at 342 , 285,253 and $140 \mathrm{~cm}^{-1}$ and the chromate pigment gave triple Raman bands at 846, 864,825 and two other bands at 380 and $340 \mathrm{~cm}^{-1}$. Lead white $\left[2 \mathrm{PbCO}_{3}\right.$. $\mathrm{Pb}(\mathrm{OH})_{2}$ ] was also detected in the light areas of the red and gave a weak band at $1050 \mathrm{~cm}^{-1}$. These Raman bands of the chromate pigment are assigned to a complex chromate mineral, hemihedrite $\left(\mathrm{ZnPb}_{10}\left(\mathrm{CrO}_{4}\right)_{6}\left(\mathrm{SiO}_{4}\right)_{2} \mathrm{~F}_{2}\right)$ [10], which has never been identified as an artistic pigment before. This mineral was discovered at the Florence Lead-Silver mine in Pinal County, Arizona [11]. It derived from the oxidation of galena, sphalerite, pyrite, and tennantite. The resulting minerals from the oxidation process are hemihedrite, wulfenite, willemite and cerussite [12]. The Raman bands appear at 847,837 and $824 \mathrm{~cm}^{-1}$ are attributed to the $\mathrm{CrO}$ stretching and the other four bands are assigned to $v 4$ bending modes $\left(376,351\right.$ and $\left.337 \mathrm{~cm}^{-1}\right)$ and $v 2$ symmetric bending modes (319 $\mathrm{cm}^{-1}$ ) [13].

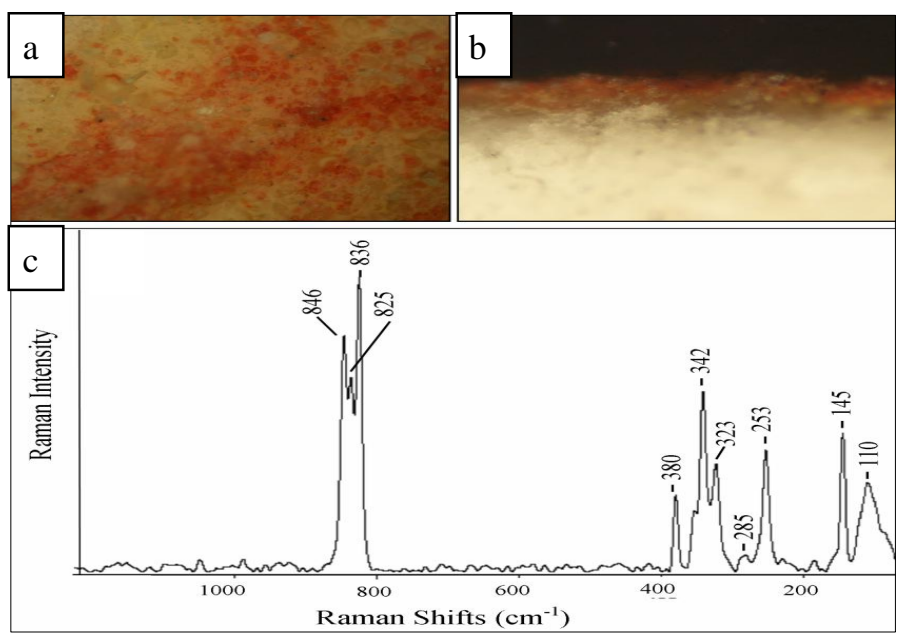

Figure (4) the red paint sample taken from decorated cornice a the fragment image, $\underline{b}$ the cross-section image, $\underline{\mathrm{c}}$ the Raman spectrum. 


\subsubsection{The brown paint sample}

The Raman spectrum of the brown paint taken from the cornice, fig. (5) gave the characteristic bands of red ochre $\left(\mathrm{Fe}_{2} \mathrm{O}_{3}+\right.$ clay + silica $)$ [13]. It gave its strong vibrational bands at 224, $291 \mathrm{~cm}^{-1}$ while the medium and weak bands were shown at 407, 494, 610, 660 $\mathrm{cm}^{-1}$. Three bands, attributed to the blue indigo pigment $\left(\mathrm{C}_{16} \mathrm{H}_{10} \mathrm{~N}_{2} \mathrm{O}_{2}\right)$, were also detected at 673,1014 and $1123 \mathrm{~cm}^{-1}$.
The presence of indigo may originate from an adjacent blue paint area that was not examined in this study. Red ochre is by far the most commonly reported red pigment from ancient Egypt starting from the pre-dynastic period. They naturally occur in the Oases of the Western desert and near Aswan [14] and were prepared by washing, levitating and grinding.

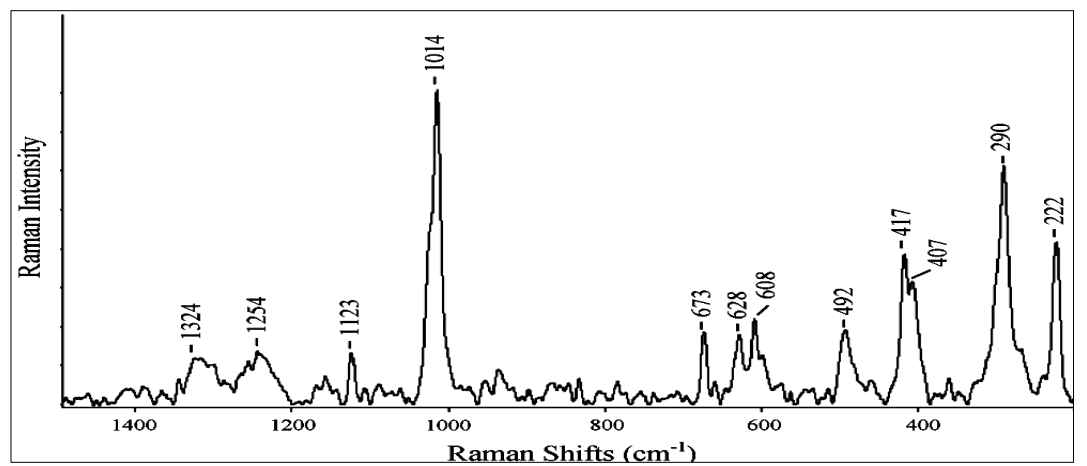

Figure (5) Raman spectrum of brown paint sample taken from the decorated cornice.

\subsubsection{The yellow paint sample}

The yellow paint area studied from the cornice revealed the Raman bands of complex mixture of cobalt yellow, fig. (6), aureolin (Potassium cobalt nitrite $\left.\mathrm{K}_{3}\left[\mathrm{Co}\left(\mathrm{NO}_{2}\right)_{6}\right]\right)$, [15] as the predominant pigment in addition to calcite and gypsum. The bands assigned to cobalt yellow revealed at 278 and 307 $\mathrm{cm}^{-1}$ while the bands of gypsum was found at 418, 669 and $1007 \mathrm{~cm}^{-1}$ and of calcite at 712 and $1085 \mathrm{~cm}^{-1}$. The principal preparation method of chrome yellow was by the acidification of solutions of cobalt salts with acetic acid followed by addition of a concentrated potassium nitrite solution. Cobalt yellow would then slowly precipitate as a yellow crystalline mass. It was first synthesised by N.W. Fischer in 1831 and was first introduced as an artist's pigment in 1861 . It does not be widely used in paintings because of its expensiveness [16].

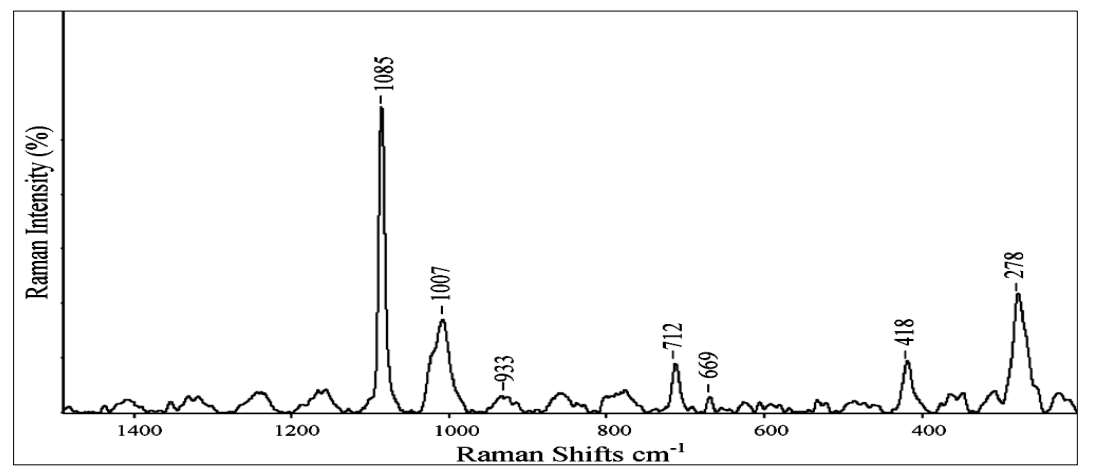

Figure (6) Raman spectrum of yellow paint sample taken from the decorated cornice.

\subsection{The paint layers of the wooden ceiling}

\subsubsection{The white paint sample}

The white pigment was sampled from the background of the ceiling. The
Raman bands at 986, 460 and $435 \mathrm{~cm}-1$, which are assigned to barium white 
(barium sulfate, $\mathrm{BaSO}_{4}$ ), fig. (7) were revealed. Synthetic barium sulfate, $\mathrm{BaSO}_{4}$, has been used since the early nineteenth century as a white pigment and an extender. The naturally occurring mineral analogue is barite which normally used as a starting mineral for producing the synthetic analogue and its synthetic version is prepared by using barite as a starting mineral which is heated with coal, forming the sulfide and gaseous by-products. After dissolving the resultant barium sulfide in water and filtering it, the sulfate can then be precipitated by adding sodium sulfate; it is filtered, washed and dried to complete the process [15]. Barium sulfate was also commonly called blanc fixe, process white and permanent white.

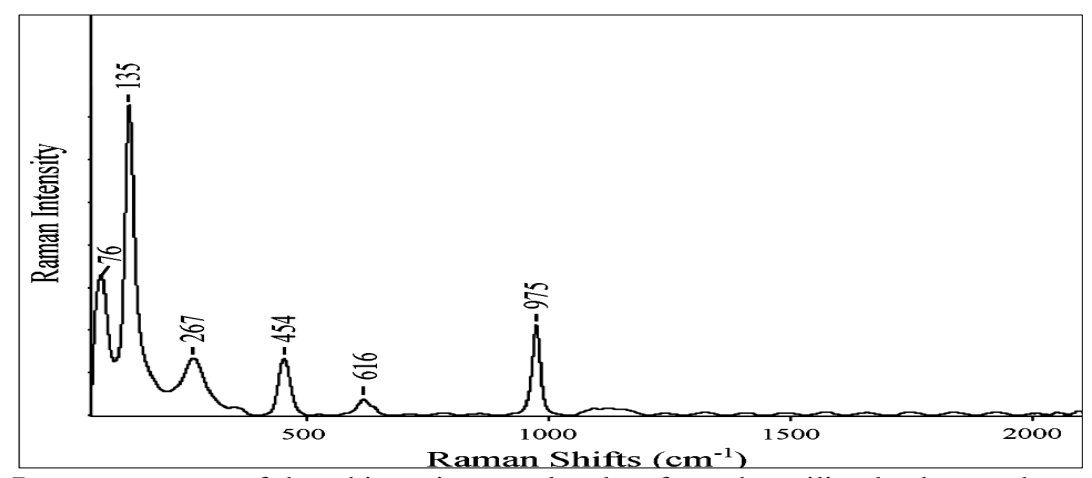

Figure (7) Raman spectrum of the white paint sample taken from the ceiling background.

\subsubsection{The gold sample}

The fragment and the crosssection images of the gold layer, fig. (8-a \& b) shows the thick bole layer underneath is apparent in the cross section image. The gold failed to give any Raman spectrum, suggesting it being real gold. The gold was applied on an orange bole layer, consisting of hydrated iron oxide and a large amount of Kaolinite. The bole layer gives a warm red tonality to the hue of the gold surface and allows further treatments of the gold leaf by burnishing [17]. The FTIR spectrum of the bole layer gave the characteristic bands assigned to the $\mathrm{OH}$ groups at 3698 and $3619 \mathrm{~cm}^{-1}$. The strong bands between 900 and 1100 $\mathrm{cm}^{-1}$ are attributed to the $\mathrm{Si}-\mathrm{O}, \mathrm{Si}-$ $\mathrm{O}-\mathrm{Si}, \mathrm{Si}-\mathrm{O}-\mathrm{Al}$ and $\mathrm{Al}-\mathrm{OH}$ groups. The bands at $1653 \mathrm{~cm}^{-1}$ along with the strong bands at 2852 and $2918 \mathrm{~cm}^{-1}$

$\mathrm{b}$ attributed to methylene groups of animal glue [4].
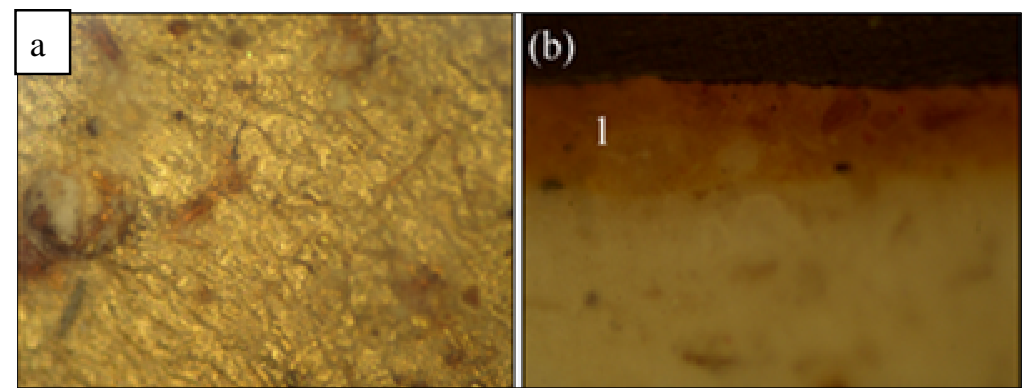

Figure (8) the gold layer taken from the relief stucco motif of the ceiling $\underline{\mathbf{a}}$ the fragment image, $\underline{\mathbf{b}}$ the cross-section image

\subsection{The white ground layer}

The FTIR analysis of the white ground layer of the ceiling, fig. (9) revealed calcium and gypsum admixed with animal glue. The absorbance bands shown at 3541,3405 and $1621 \mathrm{~cm}^{-1}$ are attributed to water molecules [4] [18] while the band at $1137 \mathrm{~cm}^{-1}$ is assigned to the sulfate group $\left(\mathrm{SO}_{4}{ }^{2-}\right)$ [4]. The 
characteristic features yielded at1428, $875,711 \mathrm{~cm}^{-1}$ are attributed to normal modes of vibration of the calcite's $\mathrm{CO}_{3}{ }^{2}$ [19]. In addition to bands at 2927 and
$2855 \mathrm{~cm}^{-1}$ which are ascribed to the methylene groups of animal glue [4] [18] [20].

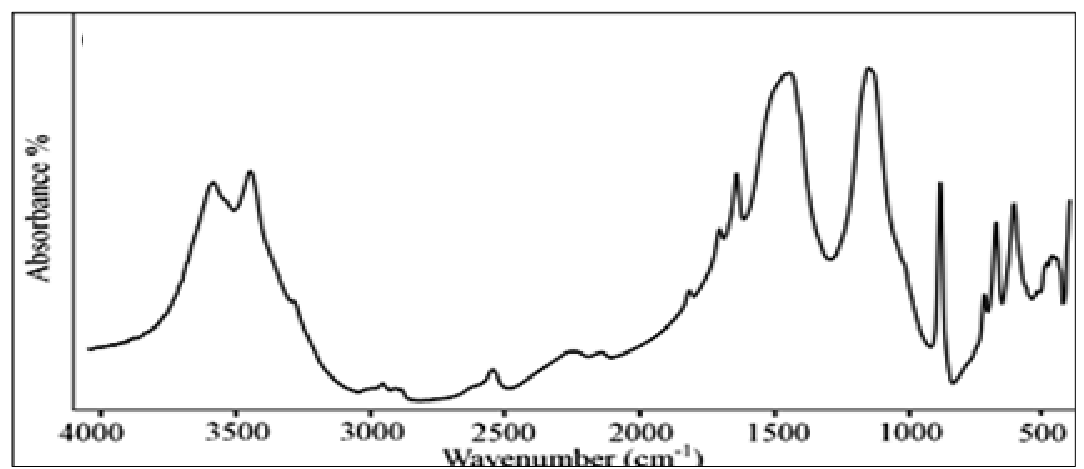

Figure (9) FTIR spectrum of the white ground layer.

\subsection{The paint media}

Two paint samples were studied by FTIR-ATR in order to determine the paint media used. The first was the blue 3.4.1. The blue paint sample

The FTIR spectrum of the blue sample, fig. (10) showed characteristic bands at 2935 and $2871 \mathrm{~cm}^{-1}$, which are assigned to $\mathrm{C}-\mathrm{H}$ stretching and $1700 \mathrm{~cm}^{-}$ ${ }^{1}$ of carbonyl group $(\mathrm{C}=\mathrm{O})$. These bands are most probably attributed to a tree resin. According to Derrick protocol for distinguishing tree resins in accordance to the position of the carbonyl and hydrocarbon absorption bands, mastic resin gives spectrum with a strong carbonyl $(\mathrm{C}=\mathrm{O})$ stretch band between $1715-1695 \mathrm{~cm}^{-1}$ and hydrocarbon $(\mathrm{C}-\mathrm{H})$ bands between 2958-2930 $\mathrm{cm}^{-1}$ and 2875-2865 $\mathrm{cm}^{-1}$ [21]. When comparing mastic resin reference sample, fig. 10-b with the spectrum of the blue paint sample, fig. 10-a, more bands were paint taken from the inscriptions' background and the second was the red sample from the decorated cornice.

identified at 1387, 1020, 982, 757 and $629 \mathrm{~cm}^{-1}$. Mastic resin attributed to the genus Pistacia sp. (family Anacardiaceae) which has four recognized species found in Mediterranean area, namely Pistacia atlantica, Pistacia khinjuk, Pistacia Lentiscus and Pistacia terebinthus [22] [23]. Pistacia atlantica (Chios turpentine) and Pistacia lentiscus (mastic resin) were used as a varnish in ancient Egypt [24] [25]. However, Pistacia khinjuk is the only source of pistacia resin in modern Egypt [26]. On the other hand, Stern et al., (2008) pointed out that the analysis of the resin cannot be used to distinguish the species due to degradation and confusion between species [27].

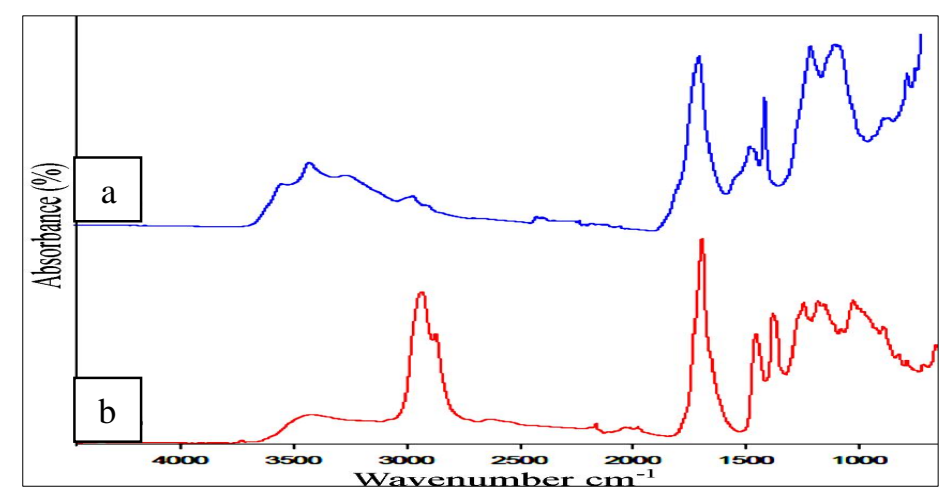

Figure (10) FTIR spectra of a the blue paint sample taken from the inscriptions' background, $\underline{\mathbf{b}}$ the reference sample of mastic resin 


\subsubsection{The red paint sample}

The FTIR spectrum of the red paint sample fig. (11-a) revealed that animal glue admixed with linseed oil was used as a paint medium. The bands attributed to animal glue shown at 1621 , 1537, 1443, 1382, 1235, 1029 and 851 $\mathrm{cm}^{-1}$, while the bands of linseed oil yielded its fatty acids $\left(\mathrm{CH}_{2}\right)$ at 2922 , $2854 \mathrm{~cm}^{-1}$ and esters $(\mathrm{C}=\mathrm{O})$ at $1727 \mathrm{~cm}^{-1}$, fig. (11-b \& c) showed the FTIR spectra of animal glue and linseed oil reference samples compared to the spectrum of the red paint sample, fig. 11-a. The results obtained from the FTIR analysis of the two samples suggest that, animal glue and linseed oil were used as a paint medium in the decorated cornice. Mastic resin could be added to the blue paint, as a paint medium, to give a different texture and thickness needed to hold the gilded inscriptions.

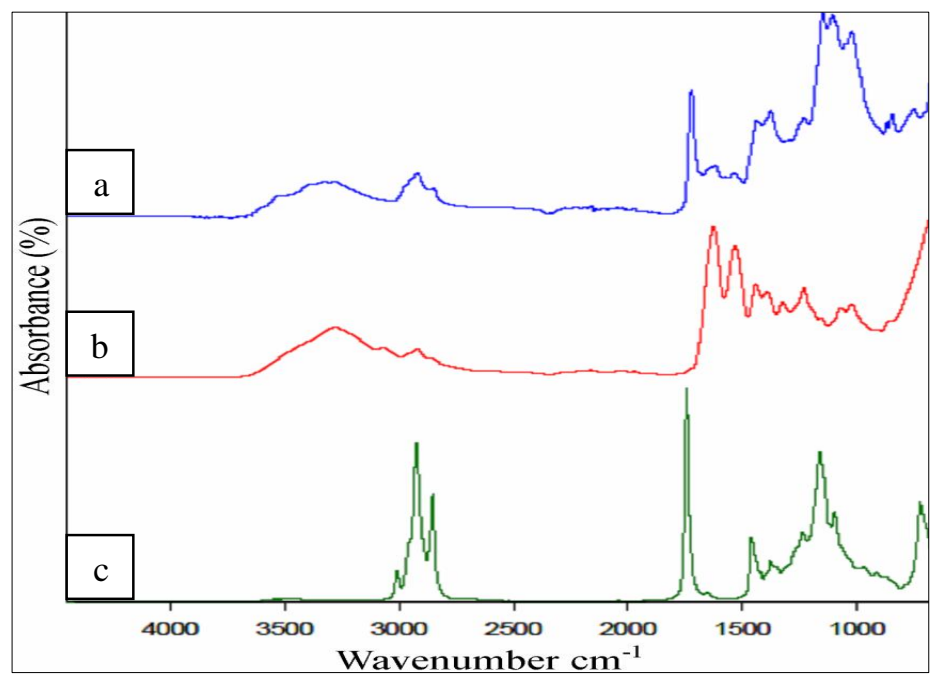

Figure (11) FTIR spectra $\underline{\mathbf{a}}$ the red paint sample taken from the decorated cornice, $\underline{\mathbf{b}}$ the reference sample of animal glue, $\underline{\mathbf{c}}$ ) the reference sample of linseed oil.

\section{Discussion}

Three studies have been performed on wall paintings and ceilings in archaeological palaces and cemeteries dated to Mohammed Ali Era [28] [29] [30]. The blue pigment identified in Sabil-Kuttab Umm Abbas was ultramarine blue which had been previously identified in the Royal family graveyards [28]. In El-Safa palace, the blue pigment identified was Prussian blue (Ali and Darwish 2011). Another blue pigment, indigo, was identified in the brown paint sample and could originate from an adjacent blue paint area of the cornice. This pigment has not been identified in Mohammed Ali artefacts but had been found in Coptic icons dated to the $18^{\text {th }}$ century [31]. The red pigment, cinnabar, was identified in this study mixed with hemihedrite and lead white. The mineral hemihedrite has not been previously identified as a pigment. Was it deliberately added by the painter or accidentally (geologically) accompanied lead white by origin? To answer this question more studies should be carried out, but the presence of hemihedrite in some red paint areas that has no lead white, could assist the first hypothesis. In our case study, cinnabar, lead white and Barium white were first detected in Mohammed Ali Era. Instead, hematite and zinc white had been used in both Abdeen palace [30] and Gawhara palace [29]. Cobalt yellow was detected in the yellow paint sample while massicot $(\mathrm{PbO})$ was identified as the yellow pigment in both Abdeen palace ceiling [30] and the Royal family graveyards [28]. The white ground layer 
on which the decorations were applied was found to consist of gypsum and calcite. The same combination was found in Abdeen place and the Royal family graveyards with addition of quartz in both instances [28] [30]. The main paint medium identified in the decorated cornice was found to be animal glue admixed with linseed oil. The same ingredients had been previously identified in the studies performed on wall paintings attributed to Mohammed Ali Era. Ali and Darwish (2011) stated that animal glue, admixed with flux seed oil, was used as paint medium in the ceiling of Abdeen Palace [30] while, in a different occasion, animal glue alone was used in the wall painting of the Royal family graveyards [28] and linseed oil was also detected in the wall paintings of El-Gawhara palce in Cairo [29]. The discovery of mastic resin as a paint medium in the blue background of the inscription is pioneer and could have been applied to obtain different properties of the blue paint, such as mechanical strength and thickness. Historically, mastic resin has not yet been detected as a paint medium in Egyptian paintings. It used to be applied as a varnish layer in ancient Egyptian funerary artefacts, precisely in the Graeco-Roman period and in the New Kingdom. In the New Kingdom, it was applied as a transparent varnish on top of funerary artefacts and mixed with bitumen or applied over a base of bitumen to imitate the appearance of the black ebony [32]. It was also used in the Graeco-Roman period (2200 BC) on a decorated sarcophagus coffin-lid as reported by Edwards et al., (2007) [33].

\section{Conclusions}

The analytical investigation of paint layers applied on sabil-kuttab Umm 'Abbas ceiling was undertaken. Both organic and inorganic constituents were subjected to examination including pigments, media, ground layer and gold layer. The analytical instruments used in this investigation were Raman microscopy, Fourier transform infra red spectroscopy coupled with attenuated total reflection (FTIR-ATR), and optical microscopy. Ultramarine and indigo were the blue pigments identified. Ultramarine was applied in the inscriptions' background while indigo was identified in the brown paint area. It most probably came from an adjacent blue area in the decorated cornice, not examined in this study. Three red pigments were detected; the first was cinnabar, which was used as a predominant pigment in the red paint area, while red ochre was used in the brown paint area. The mineral hemihedrite, which has not been previously detected as a pigment, was admixed with cinnabar to reveal the red paint. Cobalt yellow was the yellow pigment identified in this study. It was used along with calcite and gypsum to comprise the yellow paint applied in the cornice. The white pigments identified were barium sulphate and lead white. The former was used as the main pigment to obtain the white paint area of the cornice while the latter was identified in the red paint area. The white ground layer was found to consist of calcium sulfate dihydrate and calcite admixed with animal glue. Real gold leaf was used to decorate the relief stucco motifs and to paint the ornaments in the ceiling. It was applied over an orange bole layer using proteinaceous material, most probably animal glue. The paint medium identified in the cornice decorations was animal glue combined with linseed oil. This finding is not so far from the results achieved in the previous studies performed on wall paintings from Mohammed Ali Era. The interesting finding in this research was the detection of mastic resin in the blue paint sample taken from the inscriptions' background. This paint layer was completely different from the others applied in the decorated cornice in both texture and thickness. These differences may attribute to the application of mastic resin as a paint medium.

\section{References}

[1] Williams, C., (2002). Islamic monuments in Cairo: The practical guide. Cairo, New York, The American Univ. in Cairo Press, Cairo

[2] El-Gohary, M., (2011). Analytical investigations of disintegrated gran-ite surface from the un-finished obelisk in Aswan, ArchéoSciences, Vol. 35, pp: 61-79. 
[3] Burgio, L. \& Clark, R., (2001). Library of FT-Raman spectra of pigments, minerals, pigment media and varnishes, and supplement to library of Raman spectra of pigments with visible excitation, Spectrochimica Acta A, Vol. 57, pp:1491-1521.

[4] Bell, I., Clark, R. \&. Gibbs, P., (1997). Raman spectroscopic library of natural and synthetic pigments (pre-similar to $1850 \mathrm{AD}$ ), Spectrochimica Acta A: Molecular and Biomolecular Spectroscopy, Vol. 53 (12), pp: 2159-2179.

[5] Daniilia, S. \& Bikiaris, D., Burgio, L., Gavala, P., Clark, R. \& Chryssoulakis, Y., (2002). An extensive nondestructive and micro-spectroscopic study of two post-Byzantine overpainted icons of the $16^{\text {th }}$ century, Raman Spectroscopy, Vol. 33 (10), pp: 807-814.

[6] Coupry, C., (2000). Application of raman microspectrometry to art objects, Analusis, , Vol. 28 (1), pp: 39-46.

[7] Bruni, S., Cariati, F., Casadio, F. \& Toniolo, I., (1999). Identification of pigments on a XV century illuminated parchment by Raman and FTIR microspectroscopies, Spectrochimica Acta Part aMolecular and Biomolecular Spectroscopy, Vol. 55 (7-8), pp: 1371-1377.

[8] Plesters, J., (1993). Ultramarine blue, natural and artifical: Artistis` pigments: A handbook of their history and characteristics, in: Roy, A., National galarry of art, Washengton D. C.

[9] Aston, B., Harrel, A. \& Shaw, I., (2000). Stone: Ancient Egyptian materials and technology, in: Nicholson, P. \& Shaw, I. (Eds.), Cambridge Univ. Press, Cambridge.

[10] Yang, X., Sano, J., Eichler, C., Downs, R. \& Costin, G., (2007). Iranite, $\mathrm{CuPb}_{10}\left(\mathrm{CrO}_{4}\right)_{6}\left(\mathrm{SiO}_{4}\right)_{2}(\mathrm{OH})_{2}$, isomorphous with hemihedrite. Acta
Crystallographica $C, 63$, pp: i122i124.

[11] Williams, S. \& Antony, J., (1970). Hemihedrite, a new mineral from Arizona, The American Mineralogist, Vol. 55, pp: 1088-1102.

[12] Williams, P., (2005). Chromates. Encyclopedia of Geology, Elsevier Ltd, Amesterdam.

[13] Frost, R., (2004). Raman microscopy of selected chromate minerals, Raman Spectroscopy, Vol. 35, pp: 153-158.

[14] Miliani, C., Rosi, F., Daveri, A. \& Brunetti, B., (2012). Reflection infrared spectroscopy for the noninvasive in situ study of artists' pigments., Applied Physics A, Vol. 106 (2), pp: 295-307.

[15] Lucas, A., Harris J., (1962). Ancient Egyptian materials and industries, Edward Arnold. London.

[16] Ali, M., Darwish S., (2011). Comparative analytical study of the materials used in Wall painting of historical palaces, EJARS 1(1), pp: 91-100.

[17] Refaat, F., Marey, H. \& Brania, A., (2012). Analytical charecterization of Rococo paintings in Egypt: preliminary results from El-Gawhara palace at Cairo, IJCS, Vol. 3 (4) pp: 265-274.

[18] Eastaugh, N., Walsh,V., Chaplin, T. \& Siddal, R., (2004). The pigment compendium: A dictionary of historical pigments, ButterworthHeinmann, Oxford.

[19] Gettens, R. \& Stout, G., (1966). Painting materials, A short encyclopaedia, Dover Publications, Inc, New York.

[20] Crina Anca Sandu, I., Helena de Sà, M. \& Costa Pereirac, M., (2011). Ancient 'gilded' art objects from European cultural heritage: A review on different scales of characterization, Surface and Interface Analysis, Vol. 43, pp: 1134-1151.

[21] Ganitis, V., Pavlidou, E., Zorba, F., Paraskevopoulos, K. \& Bikiaris, D., (2004). A post-Byzantine icon of St 
Nicholas painted on a leather support: Microanalysis and characterisation of technique, Journal of Cultural Heritage, Vol. 5 (4), pp: 349-360.

[22] Zorba, T., Pavlidou, E., Stanojlovic, M., Bikiaris, D., Paraskevopoulos, K., Nikolic, V. \& Nikolic, P., (2006). Technique and palette of XIII $^{\text {th }}$ century painting in the monastery of Mileseva, Applied Physics A, Vol. 83, pp: 719-725.

[23] Ajo, D., Casellato, U., Fiorin, E. \& Vigato, P., (2004). Ciro Ferri's frescoes: A study of painting materials and technique by SEMEDS microscopy, X-ray diffraction, micro FT-IR and photoluminescence spectroscopy, Journal of Cultural Heritage, Vol. 5 (4), pp: 333-348.

[24] Derrick, M., Stulik, D. \& Landry, J., (1999). Infrared spectroscopy in conservation science: Scientific tools for conservation, The Getty Conservation Institute, Los Angeles, USA.

[25] Serpico, M., (1997). Mediterranean Resins in New Kingdom Egypt: A multidisciplinary approach to trade and usage, University Collage, London.

[26] Edwards, H., Stern, B., Villar, S. \& David, A., (2007). Combined FT-Raman spectroscopic and mass spectrometric study of ancient Egyptian sarcophagal fragments, Analytical and Bioanalytical Chemistry, Vol. 387, pp: 829-836.
[27] Serpico, M. \& White, R., (2000). Resins, ambers and bitumen., in: Nicholson, P. \& Shaw, I. (Eds.), Ancient Egyptian Materials and Technology Cambridge Univ. Press, Cambridge.

[28] Stern, B., Heron, C., Corr, L., Serpico, M. \& Bourriau, J., (2003). Compositional variations in aged and heated pistacia resin found in late bronze age canaanite amphorae and bowls from Amarna, Egypt, Archaeometry, Vol. 45 (3), pp: 457-469.

[29] Mills, J., White, R., (1989). The identity of the resins from the late bronze age shipwreck at Ulu Burun, Archaeometry, Vol. 31 (1), pp: 37-44.

[30] Newman, R., (1979). Some applications of infrared spectroscopy in the examination of painting materials. JAIC, Vol. 19 (1), pp: 42-62.

[31] Tackholm, V., (1974). Students' flora of Egypt. Cairo University, Cairo.

[32] Stern, B., Heron, C., Tellefsen, T. \& Serpico, M (2008). New investigations into the Uluburun resin cargo, Journal of Archaeological Science, Vol. 35 (8), pp: 1-16.

[33] Darwish, S., (2013). Scientific investigation of the materials and techniques used in a $19^{\text {th }}$ century Egyptian cemetery wall painitng (Hawsh Al-Pasha), IJCS, Vol. 4 (2), pp: 145-152. 